\title{
Aerodynamic Characteristics of Asymmetric Airfoils Blade Small Vertical Axis Wind Turbines
}

\author{
Li-Hua Zhao* and Ming Liu
}

\author{
School of Mechanical Engineering, Northeast Dianli University, Jilin 132012, China
}

\begin{abstract}
In this paper, using sliding mesh model, the numerical simulation of small vertical axis wind turbine aerodynamic performance was studied with FLUENT software. Got change rule of four same thickness and different camber's NACA series asymmetrical airfoil moment coefficient of the wind turbine and wind power machine with the tip speed ratio. Wind turbine benchmark blade around the flow field was studied. Research shows that within a certain range, small vertical axis wind turbine aerodynamic performance be promoted if the airfoil relative thickness increases. In the case of large attack angle, the wind turbine blade is easy to be separated. It provides a theoretical reference for optimal design of a small vertical axis wind turbine.
\end{abstract}

Keywords: Numerical simulation, vertical axis wind turbines, aerodynamic performance, sliding grid.

\section{INTRODUCTION}

As a renewable energy, wind energy is an important part of the world new energy development strategy [1]. Wind turbine is wind energy conversion device. According to the wind turbine main shaft and the relative position of the ground, wind turbine can be divided into wind turbines with horizontal axis and vertical axis wind turbines. Relative to the horizontal axis wind turbine, the vertical axis wind machine has the diversity of wind, no drift, simple structure, low manufacturing and running cost, etc. advantages. Vertical axis wind turbines are widely valued [2]. Small vertical axis wind machine has high utilization rate of low speed wind, low noise, safety operation and low impact on the life and the ecological environment, etc. advantages. It is more suitable for low wind speed and decentralized power demand in the region of the power supply [3].

Based on the computational fluid dynamics (CFD) numerical simulation software Fluent, the small straight blade vertical axis wind turbines are numerically simulated by use of the sliding mesh technology [4]. This paper studies the asymmetrical airfoil camber change impact on small vertical axis wind turbine aerodynamic performance. Through simulation got different series of camber airfoil moment coefficient of wind turbine impeller, under different blade tip speed ratio, the change rule of wind turbine power, and analyzes the flow field around changes of three benchmark blade wind turbine blade.

\section{THE FLOW FIELD NUMERICAL SIMULATION}

In the study, small straight blade vertical axis wind turbine rotating Mach number is less than 0.3 , the flow field

*Address correspondence to this author at the School of Mechanical Engineering, Northeast Dianli University, Jilin 132012, China;

Tel: 043264807382; E-mail: zhaolh2020@126.com in turbulent flow state air flow Reynolds number greater than $10^{5}$, so the flow field can be regarded as incompressible viscous fluid flow. According to its structure characteristics of straight blade vertical axis wind turbines, the available 2D numerical simulation approximate calculate threedimensional flow field. Therefore, in the two-dimensional unsteady incompressible flow cases, continuity equation and momentum equation of fluid flow in rectangular coordinate system ( $\mathrm{x}, \mathrm{y})$ said to [5]:

$$
\begin{aligned}
& \frac{\partial u_{x}}{\partial x}+\frac{\partial u_{y}}{\partial y}=0 \\
& \frac{\partial \mathrm{u}_{\mathrm{x}}}{\partial \mathrm{t}}+\mathrm{u}_{\mathrm{x}} \frac{\partial \mathrm{u}_{\mathrm{x}}}{\partial \mathrm{x}}+\mathrm{u}_{\mathrm{x}} \frac{\partial \mathrm{u}_{\mathrm{x}}}{\partial \mathrm{y}}=\mathrm{f}_{\mathrm{x}}-\frac{1}{\rho} \frac{\partial \mathrm{p}}{\partial \mathrm{x}} \\
& \frac{\partial \mathrm{u}_{\mathrm{y}}}{\partial \mathrm{t}}+\mathrm{u}_{\mathrm{x}} \frac{\partial \mathrm{u}_{\mathrm{y}}}{\partial \mathrm{x}}+\mathrm{u}_{\mathrm{x}} \frac{\partial \mathrm{u}_{\mathrm{y}}}{\partial \mathrm{y}}=\mathrm{f}_{\mathrm{y}}-\frac{1}{\rho} \frac{\partial \mathrm{p}}{\partial \mathrm{y}}
\end{aligned}
$$

Type (1) $\sim$ (3): $u_{i}$ is $\mathrm{i}$ direction of the velocity component, $f_{i}$ is $i$ direction of the volume force component, $i$ said $\mathrm{x}$ and $\mathrm{y} ; \rho$ is the fluid density; $\mathrm{P}$ is the pressure.

In this paper, the numerical simulation of the process is completed in the FLUENT software solver. The establishment of calculation model and the set of meshing and boundary conditions are adopting pretreatment software GAMBIT. Solver is defined as the pressure implicit solution, and the k- $\omega$ SST two equation models is used by the turbulence model in unsteady flow condition [6]. The k- $\omega$ SST two equation model is put forward by F. R. Menter, which can well simulate flow field change in far distance Wind machine wall, and satisfy the physical quantities such as pressure and speed gradient changes of airfoil near the wall turbulent flow calculation accuracy requirements at the same time. Use the calculation method of unsteady get wind turbine flow field variables change within a cycle, thus better analysis of the unsteady flow dynamic characteristics of a small vertical axis wind turbine. 
Released by NASA advisory committee NACA0014 symmetric airfoils and their corresponding different relative camber of four kinds of asymmetric airfoils are: NACA2414, NACA4414, NACA6414, and NACA8414. Airfoil thicknesses are $14 \%$ of chord. Maximum camber of asymmetric airfoils is located at $40 \%$ of the airfoil leading edge, and maximum relative thickness was $2 \%, 4 \%, 6 \%$ and 8\%. Five kinds of airfoil shape as shown in Fig. (1).

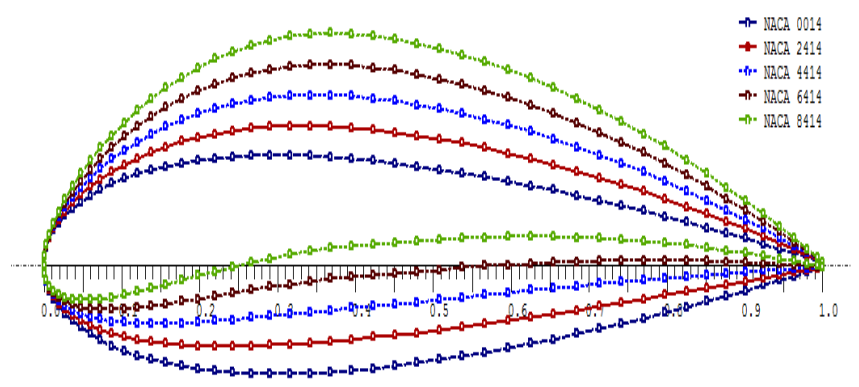

Fig. (1). Five airfoil geometry shape.

For $\mathrm{H}$ vertical axis wind turbines, because of the same of Impeller blade evvh cross-section airfoil profile, can use two dimensional plane numerical simulation method. Numerical simulation of the computational domain selection is shown in Fig. (2), in order to reduce the computational domain the influence of the peripheral flow field, shall ensure the calculation of the numerical simulation analysis have enough computational domain, select the calculation area $=-4 \mathrm{~d} \sim 4 \mathrm{~d}$, $\mathrm{x}=-5 \mathrm{~d} \sim 10 \mathrm{~d}, \mathrm{~d}$ is wind turbine diameter. Flow field use block coupling solving method, and divide the whole flow field calculation area along the impeller rotating radial into four subsystems domain. The leaf blade child domain is an annular region called rotating area., which the inside circle radius is 0.75 times the radius of wind turbine and the outside circle radius is 1.25 times the radius of wind turbine. Three sub domain is called static area except rotating area. The rotation of the wind turbine area and its adjacent radial ring sub domains using quadrilateral grid structure, with radial rotation area adjacent to the opposite direction of circular sub domains using unstructured quadrilateral mesh, connected to the computational domain boundaries of static sub domains using triangular unstructured grid. Due to large gradient changes of the pressure and speed of the blade and other physical quantities near the wall, leaf blade near the wall need high calculation accuracy. As shown in Figs. (3, 4). rotation area regional grid is for encryption processing, near the airfoil area is for grid key encryption. In order to facilitate the establishment of the grid, relative to the actual situation, ignored the meshing axis wind turbine and the influence of the blade bracket.

Boundary condition is: the numerical simulation is incompressible viscous fluid flow, on the left side of the flow field calculation domain entry is set to the velocity inlet boundary conditions, inlet flow $\mathrm{V}_{\infty}=12 \mathrm{~m} / \mathrm{s}$ and direction are along the $\mathrm{x}$ axis direction, the computational domain on the right side of the flow field is set to the pressure outlet boundary conditions for export. The computational domain outside surface and upper and lower boundary is set to no slip and no infiltrate solid wall [7]. The combination of the adjacent sub domains in sliding grid technology set to communication interface. Rotating area and blade is the same rotational speed.

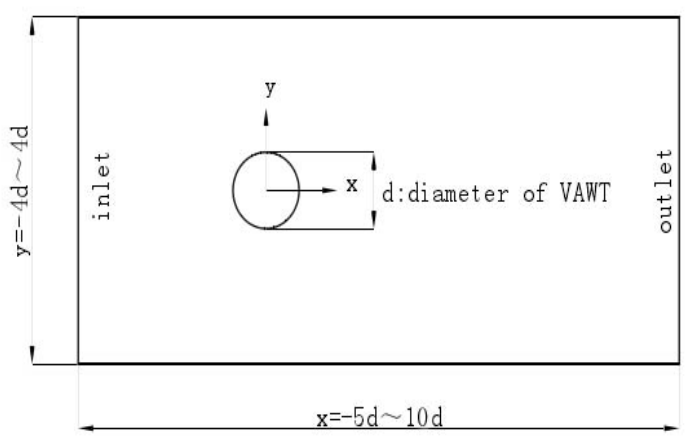

Fig. (2). Numerical simulation of the whole calculation domain.

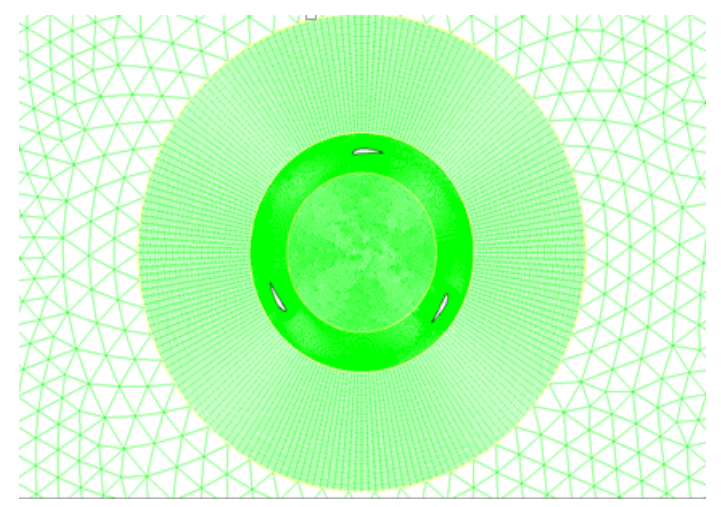

Fig. (3). Wind turbine impeller around grid map.

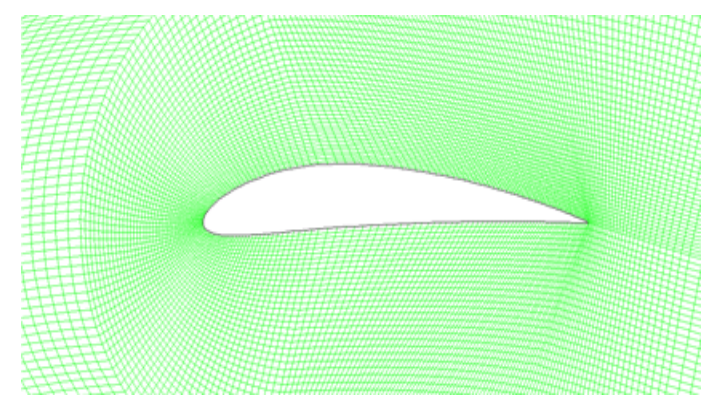

Fig. (4). Impeller blade airfoil near wall grid refinement.

The rotation of the vertical axis wind turbines diameter $\mathrm{d}$ $=1.6 \mathrm{~m}$, the airfoil chord length $\mathrm{C}=0.23 \mathrm{~m}$, the Reynolds number $\operatorname{Re}=1.9 \times 10^{5}$, Rotating the regional different rotation speed to achieve a given control of the wind turbine blade tip speed ratio. By the moment coefficient of wind turbine impeller $\mathrm{C}_{\mathrm{m}}$ can calculate impeller torque, the power of wind turbines $\mathrm{M}$ can calculate the power of wind turbines $\mathrm{P}$ and wind energy utilization coefficient $\mathrm{C}_{\mathrm{P}}$, etc. By the tip speed ratio $\lambda=(\omega R) / V_{\infty}=(2 \pi n R) / V_{\infty}$ known, changing wind turbine impeller rotational speed can get Wind turbines of the wind power coefficient $\mathrm{CP}$ and wind machine power $\mathrm{P}$, and which is under different coefficient. Computation formula is as follows:

Wind turbine torque:

$M=\frac{1}{2} C_{m} \rho V_{\infty}^{2} f R$ 
Wind turbine power:

$\mathrm{P}=\mathrm{M} \omega$

Wind energy utilization coefficient:

$C_{P}=\frac{P}{E}=\frac{2 P}{\rho f V_{\infty}^{3}}$

Type (4)-(6): $\omega$ is wind turbine impeller rotating angular velocity; $\mathrm{N}$ is the impeller rotating speed; $\lambda$ is tip speed ratio; $\mathrm{R}$ is the radius of wind turbine; $\mathrm{M}$ is the wind turbine torque; $f$ is the swept area; $\mathrm{V} \infty$ is flow velocity; $\rho$ is air density; $\mathrm{E}$ is the turbulence kinetic energy.

\section{RESULTS}

Moment coefficient is the size of wind effect on the wind machine rotating torque dimensionless quantity. It is also one of the important parameters to measure wind turbine aerodynamic characteristics. Table $\mathbf{1}$ is moment coefficient table of different wind turbine airfoils. For a given airfoil, wind turbine torque coefficient increases with the increase of tip speed ratio. When they arrive in a particular tip speed ratio, the moment coefficient of wind machine achieves the maximum value. This particular tip speed ratio is called the best tip speed ratio. The greater the tip speed ratio the wind turbine torque coefficient is smaller.

Table 1. Under different blade tip speed ratio five kinds of airfoil moment coefficient table.

\begin{tabular}{|c|c|c|c|c|c|}
\hline $\boldsymbol{\lambda}$ & $\mathbf{0 0 1 4}$ & $\mathbf{2 4 1 4}$ & $\mathbf{4 4 1 4}$ & $\mathbf{6 4 1 4}$ & $\mathbf{8 4 1 4}$ \\
\hline \hline 1.07 & 0.0052 & 0.0091 & 0.0129 & 0.0191 & 0.0211 \\
\hline 1.59 & 0.0159 & 0.0231 & 0.0326 & 0.0382 & 0.0477 \\
\hline 2.11 & 0.0305 & 0.0459 & 0.0606 & 0.0714 & 0.0764 \\
\hline 2.63 & 0.0600 & 0.0736 & 0.0824 & 0.0887 & 0.0909 \\
\hline 3.15 & 0.0797 & 0.0977 & 0.1023 & 0.1060 & 0.1081 \\
\hline 3.67 & 0.0845 & 0.0771 & 0.0941 & 0.0976 & 0.1001 \\
\hline 4.19 & 0.0554 & 0.0474 & 0.0664 & 0.0802 & 0.0795 \\
\hline 4.71 & 0.0253 & 0.0206 & 0.0351 & 0.0570 & 0.0540 \\
\hline 5.23 & 0.0002 & 0.0012 & 0.0053 & 0.0269 & 0.0211 \\
\hline
\end{tabular}

Fig. (5) is different airfoil wind turbine power variation with the tip speed ratio. In the figure clear: wind turbine power curve increase with the tip speed ratio. When reaching a certain optimum value, the wind turbine power increases with the tip speed ratio drops (similar to moment coefficient change law). For each of the airfoil, the wind turbine power is at its maximum under an optimal tip speed ratio.

With the increase of airfoil camber, corresponding to different tip speed ratio wind turbine power all has varying degrees of increase. As the airfoil camber continues to increase, NACA6414 the power of the wind turbine airfoils with NACA8414 the power of the wind turbine airfoils change rule is very small. This suggests that the airfoil camber only within a certain range change, the power of wind turbine will have significant change.
Contrast the same tip speed ratio, under a small tip speed ratio, the power of wind turbine growth will decrease and stable with the increase of airfoil camber; Under the big tip speed ratio, different airfoil wind turbine power has larger difference and change intense.

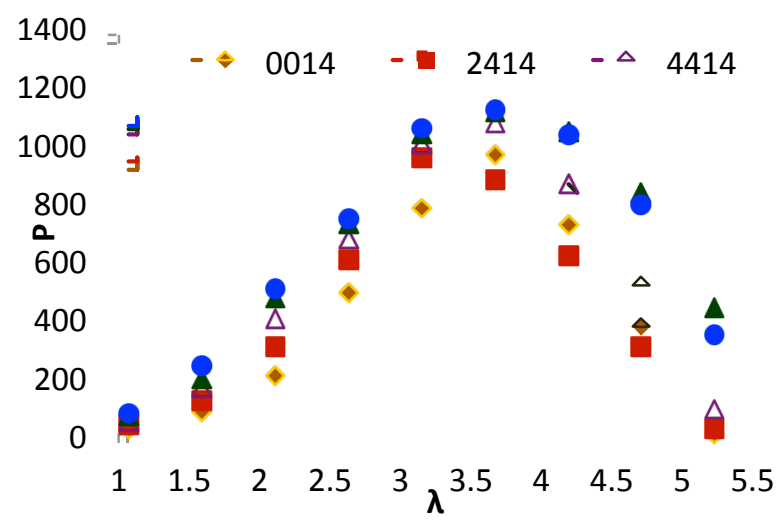

Fig. (5). The wind turbine power curve along with the change of tip speed ratio.

Within $0^{\circ} \leq \theta \leq 360^{\circ}$ the range, by the formula $\alpha=\arctan$ $(\sin \theta / \cos \theta+\lambda)(\theta$ is phase angle, $\lambda$ is tip speed ratio, $\alpha$ is angle of attack) can get to know, corresponding to angle of attack changes $-30^{\circ} \leq \alpha \leq 30^{\circ}$. Fig. (6) is in two-dimensional wind turbine model, the benchmark blade in the $30^{\circ} \leq \theta \leq$ $360^{\circ}$ flow field distribution under the initial horizontal position. The figure shows that when $60^{\circ} \leq \theta \leq 150^{\circ}$, emerged backflow phenomenon from leading edge to trailing edge. Corresponding to the inner surface (in the inside of the rotating disk) separation flow dynamic stall phenomenon occurred in the $210^{\circ} \leq \theta \leq 330^{\circ}$ range. Boundary attached again phenomena and started in the $\theta=120^{\circ}$, and completed when $\theta=180^{\circ}$. In the downstream, after half a rotating cycle, when $\theta=210^{\circ}$, emerged backflow phenomenon from leading edge to trailing edge. The surface boundary attached again phenomena and started in the $\theta=330^{\circ}$, and completed when $\theta=360^{\circ}$.

\section{CONCLUSION}

(1) The airfoil camber of small vertical axis wind turbine has great effect on the aerodynamic characteristics. In a certain range, the greater the blade airfoil camber, the greater the wind turbine torque coefficient and power.

(2) The change of the tip speed ratio has big effect on the wind turbine torque coefficient and its power. Each airfoil has an optimal tip speed ratio. Under the optimal tip speed ratio, the wind turbine can obtain larger moment coefficient and power.

(3) The same blade in different phase angle, the flow field distribution is different, and in the case of large angle of attack is prone to separation.

\section{CONFLICT OF INTEREST}

The authors confirm that this article content has no conflict of interest. 

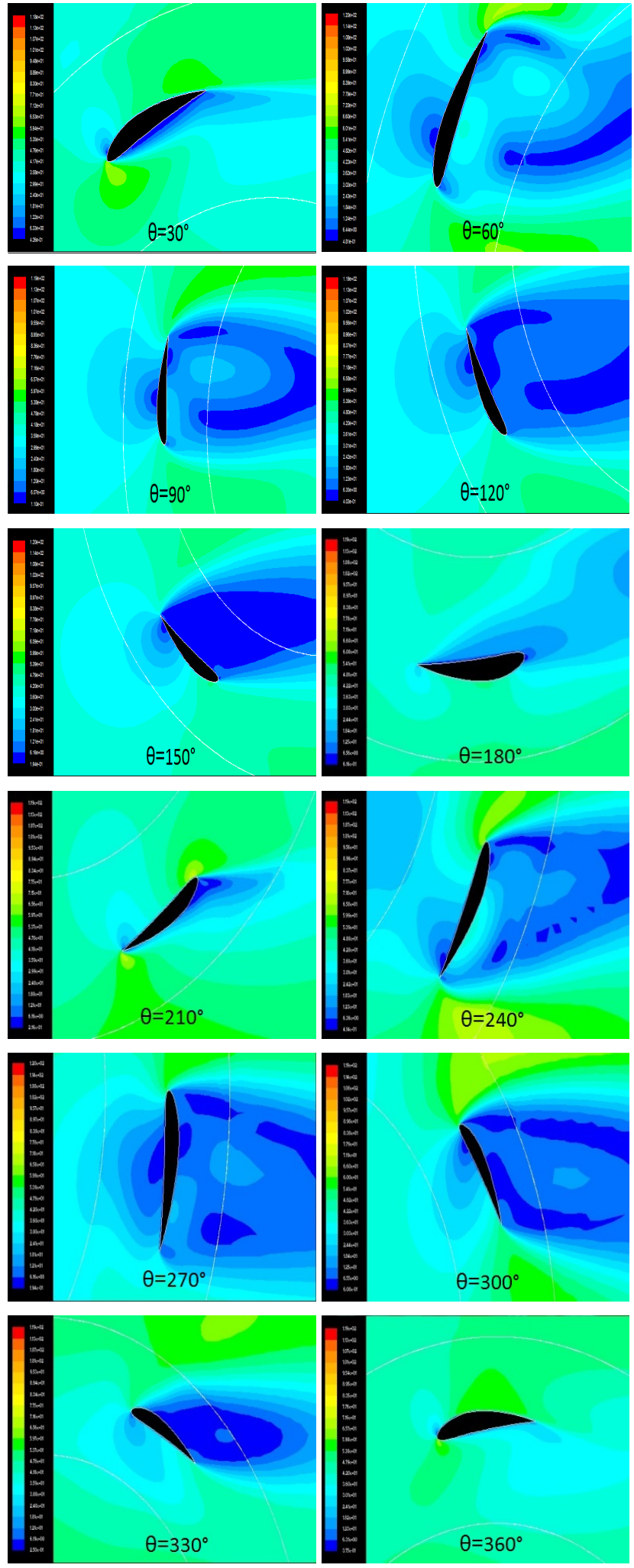

\section{ACKNOWLEDGEMENTS}

Declared none.

\section{REFERENCES}

[1] H.J. Tian, T.L. Wang, and Y. Wang, "Summarize of the development of the vertical-axis wind turbine", Applied Energy Technology, vol. 11, no. 107, pp. 22-27, November 2006.

[2] M. Islam, D.S.K. Ting, and A. Fartaj, "Aerodynamic models for Darrieus-type straight-bladed vertical axis wind turbines", Renewable and Sustainable Energy Reviews, vol. 12, no. 4, pp. 1087-1109, May 2008.

[3] Y. Li, "Vertical axis wind turbine technology (4): Lift type vertical axis wind turbine related theories", Renewable Energy Resources, vol. 27, no. 4, pp. 121-123, August 2009.

[4] C.X. Yang, F.M. Wu, and Y.L. Zhang, "Numerical simulation on unsteady rotated flow of a vertical axis wind turbine based on moving meshes", Transactions of the Chinese Society for Agricultural Machinery, vol. 40, no. 6, pp. 98-102, June 2009.

[5] Y. Mizukami, and T. Kawamura, "Numerical study of the performance of straight-wing vertical-axis-wind-turbine with two and three blades", Natural Science Report, Ochanomizu University, vol. 59, no. 2, pp. 47-54, February 2009.

[6] Y. Moryossef, and Y. Levy, "Unconditionally positive implicit procedure for two-equation turbulence models: Application to $\mathrm{k}-\omega$ turbulence models", Journal of Computational Physics, vol. 220, no. 1, pp. 88-108, December 2006.

[7] L.H. Zhao, M. Liu, and T. Lv, "Study on the aerodynamic performance of blade airfoil of vertical axis wind turbine at low Reynolds number", Information Technology Journal, vol. 12, no. 14, pp. 3042-3045, December 2013.

Fig. (6). $30^{\circ} \leq \theta \leq 360^{\circ}$ flow field distribution around the benchmark blade.

(C) Zhao and Liu; Licensee Bentham Open.

This is an open access article licensed under the terms of the Creative Commons Attribution Non-Commercial License (http://creativecommons.org/licenses/by-nc/3.0/) which permits unrestricted, non-commercial use, distribution and reproduction in any medium, provided the work is properly cited. 